\title{
Comparison between pressure-controlled ventilation with volume-guaranteed mode and volume-controlled mode in one-lung ventilation in infants undergoing video-assisted thoracoscopic surgery
}

\author{
Yu-Ping Wang ${ }^{1,2,3}$, Ying Wei ${ }^{1,2,3}$, Xiu-Ying Chen ${ }^{1,2,3}$, Long-Xin Zhang ${ }^{1,2,3}$, Min Zhou ${ }^{1,2,3}$, Jing Wang ${ }^{1,2,3}$ \\ ${ }^{1}$ Department of Anesthesiology, Fujian Maternity and Child Health Hospital, Affiliated Hospital of Fujian Medical University, Fuzhou, China; \\ ${ }^{2}$ Fujian Branch of Shanghai Children's Medical Center, Fuzhou, China; ${ }^{3}$ Department of Anesthesiology, Fujian Children's Hospital, Fuzhou, China \\ Contributions: (I) Conception and design: J Wang; (II) Administrative support: M Zhou; (III) Provision of study materials or patients: YP Wang; (IV) \\ Collection and assembly of data: Y Wei, XY Chen; (V) Data analysis and interpretation: LX Zhang; (VI) Manuscript writing: All authors; (VII) Final \\ approval of the manuscript: All authors. \\ Correspondence to: Jing Wang, MD. Department of Anesthesiology, Fujian Maternity and Child Health Hospital, Affiliated Hospital of Fujian Medical \\ University, Fuzhou, China; Fujian Branch of Shanghai Children's Medical Center, Fuzhou, China; Fujian Children's Hospital, Fuzhou, China. \\ Email: wangjing83429450@163.com.
}

\begin{abstract}
Background: The appropriate ventilation mode for one-lung ventilation (OLV) in infants undergoing video-assisted thoracoscopic surgery (VATS) remains controversial. Here we investigated the effect of ventilatory mode "pressure-controlled ventilation-volume guaranteed" (PCV-VG) on the airway pressures and oxygenation parameters by comparing it with volume-controlled ventilation (VCV).

Methods: We retrospectively analyzed the clinical data of infants aged 2 to 12 months who underwent extratracheal bronchial blockage for OLV in our center between January 2017 and August 2020. The infants were divided into two groups according to the OLV pattern: group $G(n=30$, receiving PCV-VG) and group $\mathrm{V}(\mathrm{n}=28$, receiving VCV). Mean arterial pressure (MAP), heart rate (HR), maximum inspiratory pressure $\left(\mathrm{P}_{\text {peak }}\right)$, mean airway pressure $\left(\mathrm{P}_{\text {mean }}\right)$, dynamic compliance $(\mathrm{Cdyn})$, partial arterial pressure of oxygen $\left(\mathrm{PaO}_{2}\right)$ was measured and compared between these two groups $10 \mathrm{~min}$ before OLV (T1), $30 \mathrm{~min}$ after the onset of OLV (T2) and $15 \mathrm{~min}$ after OLV (T3). The possible occurrence of hypoxemia and hypotension during OLV was monitored.

Results: Compared to group $\mathrm{V}$, group $\mathrm{G}$ had significantly higher $\mathrm{PaO}_{2}$ and $\mathrm{C}_{\text {dyn }}($ both $\mathrm{P}<0.05)$ and significantly lower $\mathrm{P}_{\text {peak }}$ and $\mathrm{P}_{\text {mean }}($ both $\mathrm{P}<0.05)$ in $\mathrm{T} 2$. However, all indicators did not show significant differences between these two groups at T1 and T3 (all P>0.05). The incidence of hypoxemia was significantly higher in group $\mathrm{V}$ than in group $\mathrm{G}(\mathrm{P}<0.05)$, while the difference in the incidence of hypotension was not statistically significant $(\mathrm{P}>0.05)$.

Conclusions: Mechanical ventilation using the PCV-VG mode is possible in infants when performing OLV during VATS. Compared to VCV, PCV-VG can offer lower $\mathrm{P}_{\text {peak }}$ and $\mathrm{P}_{\text {mean }}$, improve lung compliance, and achieve better oxygenation.
\end{abstract}

Keywords: One-lung ventilation (OLV); pressure-controlled ventilation with volume-guaranteed; infants; anesthesia

Submitted Aug 05, 2021. Accepted for publication Sep 28, 2021.

doi: $10.21037 /$ tp-21-421

View this article at: https://dx.doi.org/10.21037/tp-21-421 


\section{Introduction}

One-lung ventilation (OLV), or lung isolation, protects the healthy lung from contamination by blood or secretions at the surgical site (1). Additionally, it provides the operator with a clear surgical view to facilitate surgical operations. Thus, OLV has become a common mode of ventilation for video-assisted thoracoscopic surgery (VATS). However, OLV is not physiological and can cause adverse effects on the respiratory system (2), resulting in an imbalanced ventilation/blood flow ratio, increased intrapulmonary shunt (Qs/Qt), and decreased arterial partial pressure of oxygen $\left(\mathrm{PaO}_{2}\right)$ (3). Furthermore, pulmonary ischemiareperfusion can induce the release of inflammatory factors, leading to acute lung injury and affecting the prognosis $(4,5)$. It is necessary to choose the appropriate mode of mechanical ventilation to avoid lung injury related to respiration. Clinically, volume-controlled ventilation (VCV) is a common and classical mode of ventilation in $\operatorname{OLV}(6,7)$. Although VCV ensures a stable and accurate ventilation volume, a high peak inspiratory pressure $\mathrm{P}_{\text {peak }}$ during OLV may lead to pressure injury and other uneven air distribution in the lungs (8). The "pressure-controlled ventilation volume guaranteed" (PCV-VG) mode, also known as the "pressure-regulated volume control" (PRVC) mode, allows the anesthesia machine to reduce lung injury by minimizing intrathoracic and airway pressures in response to changes in lung compliance, while ensuring a predetermined minimum ventilation volume (9). The use of the PCV VG mode for mechanical ventilation after general anesthesia for pediatric cardiac surgery has been reported in the literature (10). The effects of VCV mode versus PCV-VG mode on oxygenation parameters and airway pressure during OLV for open heart surgery in adults have also been compared. (11) Previous studies mostly focused on the effects of different ventilation modes on respiratory mechanics or lung injury in adults during one-lung ventilation $(2,11)$, while fewer studies have compared the PCV-VG mode with the VCV mode when performing OLV in infants undergoing video-assisted thoracoscopic surgery (VATS). Here we retrospectively analyzed the medical records of infants undergoing OLV during VATS in our center from January 2017 to August 2020 to compare the effects of PCV-VG versus VCV on respiratory mechanics and $\mathrm{PaO}_{2}$. We present the following article in accordance with the STROBE reporting checklist (available at https://dx.doi.org/10.21037/tp-21-421).

\section{Methods}

All procedures performed in this study involving human participants were in accordance with the Declaration of Helsinki (as revised in 2013). The study was approved by institutional committee ethics board of Fujian Maternity and Child Health Hospital (No. 2020YJ192). Individual consent for this retrospective analysis was waived.

Infants who underwent OLV during VATS in our center from January 2017 to August 2020 were selected. The inclusion criteria were as follows: (I) American Society of Anesthesiologists (ASA) physical status II or III; (II) aged 2-12 months; (III) undergoing VATS and receiving extratracheal bronchial blockage occlusion for OLV; and (IV) PCV-VG or VCV for OLV.

Exclusion criteria included: (I) accompanied by disease(s) in another system(s); (II) conversion to open chest operation during surgery; and (III) with incomplete medical data.

According to the inclusion and exclusion criteria, 58 infants undergoing VATS were included and divided into two groups: group $\mathrm{V}(\mathrm{n}=28$, receiving $\mathrm{PCV}-\mathrm{VG})$ and group $\mathrm{G}(\mathrm{n}=30$, receiving VCV). The two groups did not show significant differences in terms of sex ratio, age, body weight, surgical time, and duration of OLV (all $\mathrm{P}>0.05$ ) (Table 1).

All infants were tracheally intubated for general

Table 1 Demographic and clinical characteristics of the two groups $\left(\bar{x}_{ \pm}\right)$

\begin{tabular}{lccc}
\hline Parameter & Group V $(\mathrm{n}=28)$ & Group $\mathrm{G}(\mathrm{n}=30)$ & $\mathrm{P}$ value \\
\hline Male/female ratio & $15 / 13$ & $16 / 14$ & - \\
Age (months) & $8.29 \pm 2.55$ & $8.40 \pm 1.99$ & 0.855 \\
Body weight $(\mathrm{kg})$ & $7.35 \pm 2.38$ & $7.05 \pm 2.62$ & 0.651 \\
Operative time $(\mathrm{min})$ & $76.12 \pm 10.72$ & $77.03 \pm 8.08$ & 0.715 \\
OLV duration $(\mathrm{min})$ & $55.11 \pm 7.97$ & $53.13 \pm 5.43$ & 0.271 \\
\hline
\end{tabular}

OLV, one-lung ventilation. 
Table 2 Comparison of the perioperative hemodynamics of the two groups $(\bar{x} \pm s)$

\begin{tabular}{lccc}
\hline Parameter & Group V $(\mathrm{n}=28)$ & Group G $(\mathrm{n}=30)$ & \\
\hline T1 & & & \\
MAP $(\mathrm{mmHg})$ & $52.50 \pm 6.93$ & $50.47 \pm 5.39$ & 0.212 \\
HR (bpm) & $115.53 \pm 12.07$ & $117.87 \pm 10.25$ & 0.428 \\
T2 & & & \\
MAP $(\mathrm{mmHg})$ & $48.89 \pm 7.91$ & $50.47 \pm 5.40$ & 0.375 \\
HR (bpm) & $116.84 \pm 12.38$ & $117.87 \pm 10.25$ & \\
T3 & & & 0.731 \\
MAP (mmHg) & $52.28 \pm 5.57$ & $50.40 \pm 6.12$ & 0.227 \\
HR (bpm) & $118.33 \pm 8.97$ & $116.63 \pm 10.09$ & 0.502 \\
\hline
\end{tabular}

MAP, the mean arterial pressure; HR, heart rate.

anesthesia. Anesthesia was induced with intravenous atropine $0.01 \mathrm{mg} / \mathrm{kg}$, propofol $2-3 \mathrm{mg} / \mathrm{kg}$, sufentanil $0.3-0.5 \mu \mathrm{g} / \mathrm{kg}$, and rocuronium $0.6 \mathrm{mg} / \mathrm{kg}$. After denitrogenation for 2 minutes, the glottis was exposed under video laryngoscopy. A blocking bronchial catheter (Tappa, Zhejiang, China) was placed, followed by the insertion of an endotracheal tube. The location of the blocking bronchial catheter was adjusted by a fiberoptic bronchoscope (FOB), and then the anesthesia machine was connected for mechanical ventilation of the double lung. Anesthesia was maintained with remifentanil $0.2-0.5 \mu \mathrm{g} / \mathrm{kg} / \mathrm{min}$, sevoflurane $1-3 \%$, and rocuronium $5-6 \mu \mathrm{g} / \mathrm{kg} / \mathrm{min}$. VCV was applied in group $\mathrm{V}$, and PCV-VG was applied in group $\mathrm{G}$. Ventilator settings during two-lung ventilation were as follows: $\mathrm{FiO}_{2}$ 0.4-0.6, PEEP 3-5 mmHg, I/E ratio 1:1.5, VT $8-10 \mathrm{~mL} / \mathrm{kg}, \mathrm{R} 30-35$ times/min, and oxygen flow 2-3 $\mathrm{L} / \mathrm{min}$. However, the ventilator settings during OLV were as follows: $\mathrm{FiO}_{2} 0.8-1.0$, PEEP $3-5 \mathrm{mmHg}$, I/E ratio 1:1.5, VT 4-6 mL/kg, R 30-35 times/min, and oxygen flow $2-3 \mathrm{~L} / \mathrm{min}$; the $\mathrm{PETCO}_{2}$ was maintained at $40-55 \mathrm{mmHg}$. A chest drainage bottle was connected at the end of the thoracic operation, and a recruitment maneuver was performed (12), during which the airway pressure was maintained at $30 \mathrm{mmHg}$ for $10 \mathrm{~s}$ by hand-controlled squeezing of the balloon, repeated 3 to 5 times. After surgery, the patient was transferred to the pediatric intensive care unit (PICU) for postoperative observation.

General data, including sex ratio, age (in months), body weight, operative time, and duration of OLV, were collected from medical records. Data related to anesthesia management were also collected, including mean arterial pressure (MAP), heart rate (HR), peak inspiratory pressure $\left(\mathrm{P}_{\text {peak }}\right)$, mean airway pressure $\left(\mathrm{P}_{\text {mean }}\right)$, dynamic compliance $\left(\mathrm{C}_{\mathrm{dyn}}\right)$. The number of patients who experienced hypoxemia (defined as oxygen saturation $\mathrm{S}_{\mathrm{P}} \mathrm{O}_{2}<90 \%$ ) and/or hypotension (defined as MAP below $20 \%$ of the baseline value) during OLV was recorded. Arterial blood was drawn for blood gas analysis and determination of $\mathrm{PaO}_{2}$ in a lateral recumbent position 10 minutes before OLV (T1), 30 minutes after the onset of OLV (T2), and 10 minutes after OLV (T3).

\section{Statistical analysis}

Statistical analysis was performed using SPSS software (23.0 version, IBM Corp., Armonk, NY). The measurement data for the normal distribution were presented as a mean \pm $\mathrm{SD}$ used by the $t$-test. Categorical variables were shown as frequency (percentage) and evaluated with the $\chi^{2}$ test. A P value less than 0.05 was defined as statistically significant.

\section{Results}

\section{Hemodynamic indicators}

The hemodynamic indicators did not show significant differences between group $\mathrm{V}$ and group $\mathrm{G}$ at $\mathrm{T} 1, \mathrm{~T} 2$, and T3 (Table 2).

$P_{\text {peak }}, P_{\text {mean }}$, and $C_{d n y}$

$\mathrm{P}_{\text {peak }}$ and $\mathrm{P}_{\text {mean }}$ were significantly lower, and $\mathrm{C}_{\mathrm{dyn}}$ was significantly higher in group $\mathrm{G}$ than in group $\mathrm{V}$ in $\mathrm{T} 2$ (all 
Table 3 Comparison of respiratory mechanics of the two groups $(\bar{x} \pm s)$

\begin{tabular}{|c|c|c|c|}
\hline Parameter & Group V (n=28) & Group $\mathrm{G}(\mathrm{n}=30)$ & $P$ value \\
\hline \multicolumn{4}{|l|}{$\mathrm{T} 1$} \\
\hline $\mathrm{P}_{\text {peak }}\left(\mathrm{cmH}_{2} \mathrm{O}\right)$ & $17.06 \pm 2.05$ & $16.07 \pm 2.83$ & 0.139 \\
\hline $\mathrm{P}_{\text {mean }}\left(\mathrm{cmH}_{2} \mathrm{O}\right)$ & $7.85 \pm 2.21$ & $7.22 \pm 2.87$ & 0.355 \\
\hline $\mathrm{C}_{\mathrm{ydn}}\left(\mathrm{mL} / \mathrm{cmH}_{2} \mathrm{O}\right)$ & $23.02 \pm 1.58$ & $22.67 \pm 2.82$ & 0.566 \\
\hline $\mathrm{PaCO}_{2}(\mathrm{mmHg})$ & $39.0 \pm 3.12$ & $38.5 \pm 4.89$ & 0.522 \\
\hline \multicolumn{4}{|l|}{ T2 } \\
\hline $\mathrm{P}_{\text {peak }}\left(\mathrm{cmH}_{2} \mathrm{O}\right)$ & $22.59 \pm 2.67^{\mathrm{ab}}$ & $19.23 \pm 3.71^{c}$ & $<0.001$ \\
\hline $\mathrm{P}_{\text {mean }}\left(\mathrm{cmH}_{2} \mathrm{O}\right)$ & $10.39 \pm 1.63^{\mathrm{ab}}$ & $9.17 \pm 2.42^{c}$ & $0.029<0.05$ \\
\hline $\mathrm{PaCO}_{2}(\mathrm{mmHg})$ & $46.50 \pm 4.44^{b}$ & $46.23 \pm 6.16^{c}$ & 0.852 \\
\hline \multicolumn{4}{|l|}{ T3 } \\
\hline $\mathrm{P}_{\text {peak }}\left(\mathrm{cmH}_{2} \mathrm{O}\right)$ & $17.36 \pm 2.09$ & $16.67 \pm 2.58$ & 0.270 \\
\hline $\mathrm{P}_{\text {mean }}\left(\mathrm{cmH}_{2} \mathrm{O}\right)$ & $7.21 \pm 2.84$ & $6.90 \pm 2.34$ & 0.651 \\
\hline $\mathrm{C}_{\mathrm{ydn}}\left(\mathrm{mL} / \mathrm{cmH}_{2} \mathrm{O}\right)$ & $21.90 \pm 4.55$ & $22.97 \pm 3.57$ & 0.322 \\
\hline $\mathrm{PaO}_{2}(\mathrm{mmHg})$ & $225.97 \pm 43.05$ & $218.77 \pm 39.53$ & 0.509 \\
\hline $\mathrm{PaCO}_{2}(\mathrm{mmHg})$ & $38.79 \pm 3.24$ & $38.37 \pm 3.24$ & 0.668 \\
\hline
\end{tabular}

${ }^{\mathrm{a}}, \mathrm{P}<0.05$, compared to group $\mathrm{G}$; ${ }^{\mathrm{b}}, \mathrm{P}<0.05$, compared to $\mathrm{T} 1$ in group $\mathrm{V} ;{ }^{\mathrm{c}}, \mathrm{P}<0.05$, compared to T1 in group $\mathrm{G}$. $\mathrm{P}_{\text {peak }}$, the peak airway pressure; $\mathrm{P}_{\text {mean }}$, the mean airway pressure; $\mathrm{C}_{\text {dyn }}$, pulmonary compliance; $\mathrm{PaO}_{2}$, arterial partial pressure of oxygen.

Table 4 Comparison of intraoperative complications between two groups

\begin{tabular}{lccc}
\hline Parameter & Group V & Group G & P value \\
\hline Number of patients & 28 & 30 & - \\
Intraoperative hypotension, $\mathrm{n}(\%)$ & $3(10.7)$ & $5(16.7)$ & 0.567 \\
Intraoperative hypoxemia, $\mathrm{n}(\%)$ & $8(28.6)^{\mathrm{a}}$ & $2(6.7)$ & 0.027 \\
\hline
\end{tabular}

${ }^{a}, \mathrm{P}<0.05$, compared to group $\mathrm{G}$.

\section{$\mathrm{P}<0.05$ ) (Table 3).}

Compared to T1, T2 had significantly elevated $\mathrm{P}_{\text {peak }}$ and $\mathrm{P}_{\text {mean }}$ and significantly decreased $\mathrm{C}_{\text {dny }}$ in groups $\mathrm{V}$ and $\mathrm{G}$.

More specifically, compared to the values at T1, Ppeak at T2 increased significantly by 5.04 (95\% CI: 3.30-6.77) and 3.17 (95\% CI: 1.56-4.77) in group V and group G, respectively (both $\mathrm{P}<0.001$ ) and $\mathrm{P}_{\text {mean }}$ at $\mathrm{T} 2$ increased significantly by 2.46 (95\% CI: $1.32-3.61)$ and 2.40 (95\% CI: 1.05-3.75) (both $\mathrm{P}<0.001)$; however, Cdyn decreased significantly by 10.04 (95\% CI: 8.99-11.08) and 8.33 (95\%
CI: 7.24-9.43) (both $\mathrm{P}<0.001$ ).

\section{$\mathrm{PaO}_{2}$ and $\mathrm{PaCO}_{2}$}

$\mathrm{PaO}_{2}$ was significantly higher in group $\mathrm{G}$ than in group $\mathrm{V}$ in $\mathrm{T} 2(\mathrm{P}<0.05)$; however, $\mathrm{PaO}_{2}$ did not show significant differences in $\mathrm{T} 1$ and $\mathrm{T} 3$ (both $\mathrm{P}>0.05$ ).

$\mathrm{PaO}_{2}$ decreased significantly in $\mathrm{T} 2$ than in $\mathrm{T} 1$ in both group V [by 104.64 (95\% CI: 81.68-127.61)] and group G [by 75.43 (95\% CI: 50.66-100.20)] (both $\mathrm{P}<0.05)$ (Table 4). 
$\mathrm{PaCO}_{2}$ did not show significant differences between two groups in T1, T2, and T3 (all $\mathrm{P}>0.05$ ).

$\mathrm{PaCO}_{2}$ increased significantly in $\mathrm{T} 2$ than in $\mathrm{T} 1$ in both group V [by 7.500 (95\% CI: 5.35-9.65)] and group G [by 7.933 (95\% CI: 4.93-10.94)] (both $\mathrm{P}<0.05$ ) (Table 4).

\section{Incidences of bypotension and bypoxia}

Hypoxemia and hypotension were observed in both groups. The incidence of hypoxemia was significantly higher in group $\mathrm{V}$ than in group $\mathrm{G}(\mathrm{P}<0.05)$, whereas the incidence of hypotension was not significantly different $(\mathrm{P}>0.05)$.

\section{Discussion}

This retrospective study found that the PCV-VG mode provided lower $\mathrm{P}_{\text {peak }}$ and $\mathrm{P}_{\text {mean }}$, higher lung compliance, and better oxygenation during OLV in infants undergoing VATS.

Compared with thoracotomy, thoracoscopic surgery has the advantages of small incision, less postoperative pain, faster recovery and shorter hospital stay (13). One lung ventilation is an essential anesthesia technique in thoracoscopic surgery. OLV provides a good environment for VATS by allowing ventilation through the healthy lung, while allowing the intentional collapse of the lung on the operative side, keeping the operative field relatively still (14). OLV can also prevent blood or secretions from the diseased side from entering the healthy side during surgery, preventing crossinfection in both lungs. However, based on characteristics of infant respiratory physiology, it is prone tendency toward shunt and hypoxemia when implementing OLV through thoracoscopy (15). As a non-physiological ventilation mode, OLV, when performed inappropriately, can lead to ventilatorinduced lung injury (VILI). Excessively high $\mathrm{P}_{\text {peak }}$, prolonged inspiratory time, and partial alveolar hyperinflation due to the uneven distribution of gas in the lungs are the main causes of VILI (16). Due to their small airway lumen, infants and children have high airway resistance and poor lung compliance; compared to adults, they are more prone to high airway pressure and ventilation/blood flow disproportion and are more likely to develop lung dysfunction. It is necessary to choose the appropriate mode of mechanical ventilation to avoid lung injury related to respiration.

VCV is currently a common ventilation mode during anesthesia. In the VCV mode, the flow rate gradually increases during the ventilator inspiratory phase. Therefore, the pressure of the airways gradually increases, with small airways and alveoli expanding until the set tidal volume is converted to the expiratory phase in a set time.

In our current study, we found in both groups that $C_{\text {dyn }}$ was significantly lower in $\mathrm{T} 2$ compared to $\mathrm{T} 1$ and returned to the baseline level in T3. During OLV, the elasticity of lung tissue, thoracic compliance, and resistance to airways changes dramatically due to the specific body position, affecting lung compliance. In our current study, $\mathrm{C}_{\mathrm{dyn}}$ was significantly higher in group $\mathrm{G}$ than in group $\mathrm{V}$ at $\mathrm{T} 2$, i.e., during OLV, and $\mathrm{P}_{\text {peak }}$ and $\mathrm{P}_{\text {mean }}$ were significantly lower in group $\mathrm{G}$ than in group $\mathrm{V}$. Lung compliance decreases during OLV. To ensure the delivery of a preset tidal volume to the lungs of a pediatric patient, the PCV-VG mode automatically adjusts the air delivery rate and the airway pressure level according to reduced lung compliance, resulting in a prolonged inspiratory phase and the lowest $\mathrm{P}_{\text {peak }}$; it is adjusted to the expiratory mode after the target tidal volume is reached. A meta-analysis found significantly lower $\mathrm{P}_{\text {peak }}(\mathrm{P}<0.00001)$ in the $\mathrm{PCV}-\mathrm{VG}$ group than in the VCV group in adults undergoing OLV (17).

During mechanical ventilation, a change in intrathoracic pressure can affect the venous return and thus circulatory function. In our current study, there was no significant difference in the incidences of MAP and hypotension during OLV between the two groups.

We also found no statistical differences in $\mathrm{PaO}_{2}$ and $\mathrm{PaCO}_{2}$ between the PCV-VG mode and the VCV mode in $\mathrm{T} 1$ and $\mathrm{T} 3$ during double lung ventilation. In T2, however, although the $\mathrm{PO}_{2}$ value was above $100 \mathrm{mmHg}$ in both groups, it was significantly higher in group $G$ than in group V. Similarly, the incidence of hypoxemia was significantly higher in group $\mathrm{V}$ than in group $\mathrm{G}$. Possible explanations may include the following: First, VCV is associated with high $\mathrm{P}_{\text {peak }}$ during OLV, which aggravates the mechanical strain on the lung tissue (18). In addition, it will worsen the uneven distribution of gas in the lungs, resulting in alveolar hyperinflation. Therefore, more blood flows to the nonventilated lung, weakening hypoxic pulmonary vasoconstriction and increasing the incidence of hypoxemia (19). Second, the decrease in airflow during the air delivery pattern of the PCV-VG mode makes the airway pressure reach its maximum at the beginning of inspiration, which will be maintained throughout the inspiratory phase. Small airways and alveolar tissues open in the shortest time, so even tissues with low compliance can receive a certain amount of air, and the constant plateau pressure is more conducive to oxygen diffusion. Therefore, it possibly reduces the injury caused by high airway pressure, improving intrapulmonary shunting to some extent, and 
lung compliance, which facilitates alveolar ventilation and oxygenation. Ghabach et al. (20) and Mahmoud et al. (11) also found that PCVVG significantly reduced airway pressure and improved oxygenation (compared to VCV).

There are still some limitations to this study. This study is a retrospective single-center study involving a small sample size, and there may have been some selective deviation. Besides, this study was a retrospective study, not a prospective case-control study, which also limited its statistical potency, but we still believed that such a study had certain clinical significance. Future research needed to consider variations of factors and complete a larger sample to confirm our conclusions.

\section{Conclusions}

Mechanical ventilation using the PCV-VG mode is feasible in infants when performing OLV during VATS. Compared to $\mathrm{VCV}, \mathrm{PCV}-\mathrm{VG}$ can offer lower $\mathrm{P}_{\text {peak }}$ and $\mathrm{P}_{\text {mean }}$, improve lung compliance, and achieve better oxygenation.

\section{Acknowledgments}

Funding: None.

\section{Footnote}

Reporting Checklist: The authors have completed the STROBE reporting checklist. Available at https://dx.doi. org/10.21037/tp-21-421

Data Sharing Statement: Available at https://dx.doi. org/10.21037/tp-21-421

Conflicts of Interest: All authors have completed the ICMJE uniform disclosure form (available at https://dx.doi. org/10.21037/tp-21-421). The authors have no conflicts of interest to declare.

Ethical Statement: The authors are accountable for all aspects of the work in ensuring that questions related to the accuracy or integrity of any part of the work are appropriately investigated and resolved. All procedures performed in this study involving human participants were in accordance with the Declaration of Helsinki (as revised in 2013). The study was approved by institutional committee ethics board of Fujian Maternity and Child Health Hospital (No. 2020YJ192). Individual consent for this retrospective analysis was waived.

Open Access Statement: This is an Open Access article distributed in accordance with the Creative Commons Attribution-NonCommercial-NoDerivs 4.0 International License (CC BY-NC-ND 4.0), which permits the noncommercial replication and distribution of the article with the strict proviso that no changes or edits are made and the original work is properly cited (including links to both the formal publication through the relevant DOI and the license). See: https://creativecommons.org/licenses/by-nc-nd/4.0/.

\section{References}

1. Lohser J, Slinger P. Lung Injury After One-Lung Ventilation: A Review of the Pathophysiologic Mechanisms Affecting the Ventilated and the Collapsed Lung. Anesth Analg 2015;121:302-18.

2. Yao W, Yang M, Cheng Q, et al. Effect of PressureControlled Ventilation-Volume Guaranteed on One-Lung Ventilation in Elderly Patients Undergoing Thoracotomy. Med Sci Monit 2020;26:e921417.

3. Karzai W, Schwarzkopf K. Hypoxemia during onelung ventilation: prediction, prevention, and treatment. Anesthesiology 2009;110:1402-11.

4. Bastin AJ, Sato H, Davidson SJ, et al. Biomarkers of lung injury after one-lung ventilation for lung resection. Respirology 2011;16:138-45.

5. Licker M, Fauconnet P, Villiger Y, et al. Acute lung injury and outcomes after thoracic surgery. Curr Opin Anaesthesiol 2009;22:61-7.

6. Zhang L, Wang YP, Chen XF, et al. Effects of bronchial blockers on gas exchange in infants with one-lung ventilation: a single-institutional experience of 22 cases. Transl Pediatr 2020;9:802-8.

7. Sentürk M. New concepts of the management of one-lung ventilation. Curr Opin Anaesthesiol 2006;19:1-4.

8. Lohser J. Evidence-based management of one-lung ventilation. Anesthesiol Clin 2008;26:241-72, v.

9. Samantaray A, Hemanth N. Comparison of two ventilation modes in post-cardiac surgical patients. Saudi J Anaesth 2011;5:173-8.

10. Kocis KC, Dekeon MK, Rosen HK, et al. Pressureregulated volume control vs volume control ventilation in infants after surgery for congenital heart disease. Pediatr Cardiol 2001;22:233-7.

11. Mahmoud K, Ammar A, Kasemy Z. Comparison Between Pressure-Regulated Volume-Controlled and Volume- 
Controlled Ventilation on Oxygenation Parameters, Airway Pressures, and Immune Modulation During Thoracic Surgery. J Cardiothorac Vasc Anesth 2017;31:1760-6.

12. Duff JP, Rosychuk RJ, Joffe AR. The safety and efficacy of sustained inflations as a lung recruitment maneuver in pediatric intensive care unit patients. Intensive Care Med 2007;33:1778-86.

13. Shah R, Reddy AS, Dhende NP. Video assisted thoracic surgery in children. J Minim Access Surg 2007;3:161-7.

14. Hale JE, Meador MR, Mossad EB. Lung separation in children: Options and impact on gas exchange and lung compliance. Paediatr Anaesth 2019;29:915-9.

15. Semmelmann A, Kaltofen H, Loop T. Anesthesia of thoracic surgery in children. Paediatr Anaesth 2018;28:326-31.

16. Slutsky AS, Ranieri VM. Ventilator-induced lung injury. N Engl J Med 2013;369:2126-36.

17. Schick V, Dusse F, Eckardt R, et al. Comparison of Volume-Guaranteed or -Targeted, Pressure-Controlled Ventilation with Volume-Controlled Ventilation during

Cite this article as: Wang YP, Wei Y, Chen XY, Zhang LX, Zhou M, Wang J. Comparison between pressurecontrolled ventilation with volume-guaranteed mode and volume-controlled mode in one-lung ventilation in infants undergoing video-assisted thoracoscopic surgery. Transl Pediatr 2021;10(10):2514-2520. doi: 10.21037/tp-21-421
Elective Surgery: A Systematic Review and Meta-Analysis. J Clin Med 2021;10:1276.

18. Kim KN, Kim DW, Jeong MA, et al. Comparison of pressure-controlled ventilation with volume-controlled ventilation during one-lung ventilation: a systematic review and meta-analysis. BMC Anesthesiol 2016;16:72.

19. Kozian A, Schilling T, Schütze H, et al. Ventilatory protective strategies during thoracic surgery: effects of alveolar recruitment maneuver and low-tidal volume ventilation on lung density distribution. Anesthesiology 2011;114:1025-35.

20. Ghabach MB, El Hajj EM, El Dib RD, et al. Ventilation of Nonparalyzed Patients Under Anesthesia with Laryngeal Mask Airway, Comparison of Three Modes of Ventilation: Volume Controlled Ventilation, Pressure Controlled Ventilation, and Pressure Controlled Ventilation-volume Guarantee. Anesth Essays Res 2017;11:197-200.

(English Language Editor: J. Chapnick) 